\title{
Top five ethical lessons of COVID-19 that the world must learn
}

\section{[version 1; peer review: 2 approved]}

\author{
Maxwell J. Smith (i1), Aasim Ahmad², Thalia Arawi3 ${ }^{3}$ Angus Dawson4, \\ Ezekiel J. Emanuel ${ }^{5}$, T. Garani-Papadatos ${ }^{6}$, Prakash Ghimire ${ }^{7}$, Zubairu Iliyasu (iD) \\ Ruipeng Lei ${ }^{9}$, Ignacio Mastroleo (D10, Roli Mathur11, Joseph Okeibunor(D12, \\ Michael Parker (Di)13, Carla Saenz ${ }^{14}$, Beatriz Thomé (D)15, Ross E.G. Upshur (D)16, \\ Teck Chuan Voo (iD) 17
}

\footnotetext{
${ }^{1}$ University of Western Ontario, London, Ontario, Canada

${ }^{2}$ The Kidney Centre Post Graduate Training Institute, Karachi, Pakistan

${ }^{3}$ American University of Beirut, Beirut, Lebanon

${ }^{4}$ University of Sydney, Sydney, New South Wales, Australia

5 University of Pennsylvania, Philadelphia, Pennsylvania, USA

6University of West Attica, Athens, Greece

${ }^{7}$ Tribhuvan University, Kathmandu, Nepal

${ }^{8}$ Bayero University Kano, Kano, Nigeria

${ }^{9}$ Huazhong University of Science and Technology, Wuhan, China

${ }^{10}$ National Scientific and Technical Research Council, Buenos Aires, Argentina

${ }^{11}$ National Center for Disease Informatics and Research (ICMR-NCDIR), Bengaluru, India

12University of Nigeria Nsukka, Nsukka, Nigeria

13University of Oxford, Oxford, UK

${ }^{14}$ Pan American Health Organization, Washington, DC, USA

15Universidade Federal de São Paulo, São Paulo, Brazil

16University of Toronto, Toronto, Ontario, Canada

${ }^{17}$ National University of Singapore, Singapore, Singapore
}

V1 First published: 29 Jan 2021, 6:17

https://doi.org/10.12688/wellcomeopenres.16568.1

Latest published: 29 Jan 2021, 6:17

https://doi.org/10.12688/wellcomeopenres.16568.1

\section{Abstract}

As the world reflects upon one year since the first cases of coronavirus disease 2019 (COVID-19) and prepare for and experience surges in cases, it is important to identify the most crucial ethical issues that might lie ahead so that countries are able to plan accordingly. Some ethical issues are rather obvious to predict, such as the ethical issues surrounding the use of immunity certificates, contact tracing, and the fair allocation of vaccines globally. Yet, the most significant ethical challenge that the world must address in the next year and beyond is to ensure that we learn the ethical lessons of the first year of this pandemic. Learning from our collective experiences thus far constitutes our greatest moral obligation. Appreciating that decisionmaking in the context of a pandemic is constrained by unprecedented complexity and uncertainty, beginning in June 2020 , an international

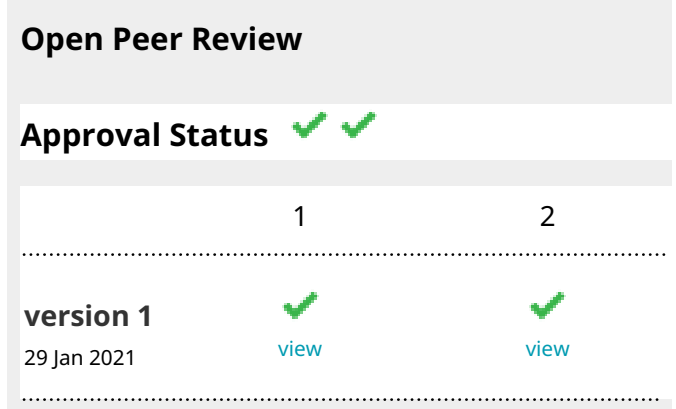

1. Gustavo Ortiz-Millan ID, National

Autonomous University of Mexico, Mexico

City, Mexico

2. Gamal Serour, Al Azhar University, Cairo,

Egypt

Any reports and responses or comments on the 
group of 17 experts in bioethics spanning 15 countries (including low-, middle-, and high-income countries) met virtually to identify what we considered to be the most significant ethical challenges and accompanying lessons faced thus far in the COVID-19 pandemic. Once collected, the group met over the course of several virtual meetings to identify challenges and lessons that are analytically distinct in order to identify common ethical themes under which different challenges and lessons could be grouped. The result, described in this paper, is what this expert group consider to be the top five ethical lessons from the initial experience with COVID-19 that must be learned.

Keywords

COVID-19, Ethics

This article is included in the Global Infectious

GLIDE- Disease Ethics Collaborative (GLIDE) gateway.

This article is included in the Coronavirus

(COVID-19) collection.

This article is included in the Epidemic Ethics:

Global issues in ethics and COVID-19 collection. 


\section{Corresponding author: Maxwell J. Smith (maxwell.smith@uwo.ca)}

Author roles: Smith MJ: Conceptualization, Formal Analysis, Writing - Original Draft Preparation, Writing - Review \& Editing; Ahmad A: Conceptualization, Formal Analysis, Writing - Original Draft Preparation, Writing - Review \& Editing; Arawi T: Conceptualization, Formal Analysis, Writing - Original Draft Preparation, Writing - Review \& Editing; Dawson A: Conceptualization, Formal Analysis, Writing Original Draft Preparation, Writing - Review \& Editing; Emanuel EJ: Conceptualization, Formal Analysis, Writing - Original Draft Preparation, Writing - Review \& Editing; Garani-Papadatos T: Conceptualization, Formal Analysis, Writing - Original Draft Preparation, Writing - Review \& Editing; Ghimire P: Conceptualization, Formal Analysis, Writing - Original Draft Preparation, Writing - Review \& Editing; Iliyasu Z: Conceptualization, Formal Analysis, Writing - Original Draft Preparation, Writing - Review \& Editing; Lei R: Conceptualization, Formal Analysis, Writing - Original Draft Preparation, Writing - Review \& Editing; Mastroleo I: Conceptualization, Formal Analysis, Writing - Original Draft Preparation, Writing - Review \& Editing; Mathur R: Conceptualization, Formal Analysis, Writing - Original Draft Preparation, Writing - Review \& Editing; Okeibunor J: Conceptualization, Formal Analysis, Writing - Original Draft Preparation, Writing - Review \& Editing; Parker M: Conceptualization, Formal Analysis, Writing - Original Draft Preparation, Writing Review \& Editing; Saenz C: Conceptualization, Formal Analysis, Writing - Original Draft Preparation, Writing - Review \& Editing; Thomé B : Conceptualization, Formal Analysis, Writing - Original Draft Preparation, Writing - Review \& Editing; Upshur REG: Conceptualization, Formal Analysis, Writing - Original Draft Preparation, Writing - Review \& Editing; Voo TC: Conceptualization, Formal Analysis, Writing Original Draft Preparation, Writing - Review \& Editing

Competing interests: No competing interests were disclosed.

Grant information: This work was supported by the Wellcome Trust through funding to the Public Health Emergency Preparedness and Response Ethics Network (PHEPREN) [221559]. PHEPREN funding is provided by The Wellcome Trust and the World Health Organization. The funders had no role in study design, data collection and analysis, decision to publish, or preparation of the manuscript.

Copyright: ( 2021 Smith MJ et al. This is an open access article distributed under the terms of the Creative Commons Attribution License , which permits unrestricted use, distribution, and reproduction in any medium, provided the original work is properly cited.

How to cite this article: Smith MJ, Ahmad A, Arawi T et al. Top five ethical lessons of COVID-19 that the world must learn [version 1; peer review: 2 approved] Wellcome Open Research 2021, 6:17 https://doi.org/10.12688/wellcomeopenres.16568.1

First published: 29 Jan 2021, 6:17 https://doi.org/10.12688/wellcomeopenres.16568.1 
As many countries reflect upon one year since the first cases of coronavirus disease 2019 (COVID-19) and prepare for and experience surges in cases, it is important to identify the most crucial ethical issues that might lie ahead so that countries are able to plan accordingly. Some ethical issues are rather obvious to predict, such as the ethical issues surrounding the use of immunity certificates ${ }^{1}$, contact tracing ${ }^{2}$, and the fair allocation of vaccines ${ }^{3}$. Yet, the most significant ethical challenge that the world must address is ensuring that we learn the ethical lessons from earlier waves of this pandemic. Learning from our collective experiences thus far constitutes our greatest moral obligation, as failing to learn from our prior experiences and prevent the ethical shortcomings of earlier waves of the pandemic would represent a transgression of the ethical obligation to use available knowledge, evidence, and experience to protect and promote public health ${ }^{4}$. Appreciating that decision-making in the context of a pandemic is constrained by unprecedented complexity and uncertainty, beginning in June 2020, an international group of 17 experts in bioethics spanning 15 countries (including low-, middle-, and high-income countries) met virtually to identify what we considered to be the most significant ethical challenges and accompanying lessons faced thus far in the COVID-19 pandemic. Once collected, the group met over the course of several virtual meetings to identify challenges and lessons that are analytically distinct in order to identify common ethical themes under which different challenges and lessons could be grouped. The result, described below, is what this expert group consider to be the top five ethical lessons from the initial experience with COVID-19 that must be learned.

\section{We must learn to prepare adequately based on previous experience}

The primary obligation of governments is to protect their populations from threats to their freedom and well-being. Yet, despite the laudable and often undervalued efforts of public health and emergency preparedness experts, we have collectively failed to make the necessary preparations for pandemics despite knowledge about the risks. We have also been slow to learn from the experiences of other countries who were affected earlier in this pandemic. Adequate preparation is an ethical obligation because it is, all other things being equal, better to prevent harms from occurring rather than only respond once they emerge. Consequently, where we know harms will occur, we have an ethical obligation to mitigate them. Features of public health systems such as adequate surveillance, stockpiles of personal protective equipment, testing, contact tracing, the identification of at-risk populations, and other non-pharmaceutical interventions are crucial to the prevention and mitigation of harms, and must be strengthened, particularly in the absence of a widely available vaccine and the existence of only limited treatments. Given the world's experience with COVID-19, an ethical obligation exists to learn from previous experience and aggressively seek to prevent these predictable harms from occurring in subsequent waves.

\section{We must learn to better articulate and prioritize overarching goals}

The policies and measures implemented in response to the pandemic should align with a set of clear and justified overarching goals. Such goals inevitably engage with important and often conflicting ethical considerations. In the COVID-19 pandemic, there has been a lack of clarity as to whether the overarching goal has been to flatten the curve, protect the acute health care system, reduce morbidity and mortality, protect the health of disadvantaged communities, protect those most vulnerable to infection, minimize extreme poverty, mitigate economic loss, or some combination of the above. Even if these were all possible goals for the pandemic response, more needs to be done to understand which goals should be prioritized over others, in what contexts, and at what point in the response, in addition to what justifies any proposed ranking.

The ethical case for requiring clear and justified overarching goals is that they are key to setting ethical and fair priorities for the distribution of vaccines, therapeutics, diagnostics, and other human and economic resources. Where resources are scarce, choices will have to be made about how they are allocated. One option is to distribute goods randomly, so that all have an equal chance of any benefit. However, many people believe that this is unethical, and that we have good grounds for choosing to distribute unequally taking into account other morally relevant features such as reducing mortality and morbidity directly and indirectly caused by the pandemic, reducing the social and economic consequences of the pandemic with particular emphasis on reducing health inequities, mitigating poverty, and ensuring continuity of important goods like education, and returning society to full functionality.

\section{We must learn to work collaboratively}

The most important aspect of a pandemic such as COVID-19 is that it is a global problem and therefore requires a global response. Even a focus on achieving what is best in terms of national self-interest requires solidarity across nations and between peoples to be most effective. The best protection for every country is to act together. We think it is therefore regrettable and unjust that some countries have chosen this moment to withdraw global social capital, support, influence, and funding. It is estimated that $\$ 3.4$ billion (USD) a year is needed to fund the "global functions" of WHO pandemic preparedness, but funds have fallen woefully short of this target ${ }^{5}$.

Other examples of failures to work together for the benefit of all include the lack of genuine international collaboration for surveillance and effective response as envisioned by the International Health Regulations ${ }^{6}$, including early institution of mitigation measures, as well as the lack of collaboration within and between the countries in controlling access to personal protective equipment (PPE), diagnostic test kits, and reagents. Leaving the market to distribute essential goods during a global health emergency results in increased injustice because of the unequal access to available equipment and trained human resources.

\section{We must learn to protect the most vulnerable individuals and populations}

The pandemic and every pandemic policy will impact groups in a population unequally, and prior disadvantage is likely to be exacerbated. While it may often be difficult to anticipate the unforeseen consequences of prolonged public health and social measures on disadvantaged populations, we should 
acknowledge that prior disadvantage is likely to be exacerbated and plan for it. Support and resources must be distributed unequally to bring about greater equity. For example, poor preparedness for a pandemic like COVID-19 and the subsequent response imposed new norms of containment, physical distancing, and confinement orders without adequate financial support and other follow-up measures to mitigate their risks and harms. Consequently, about 100 million people are likely to be thrown into extreme poverty ${ }^{7}$. In low- and middle-income countries, millions of low-paid daily wagers and migrant workers suddenly lost their jobs and were rendered homeless, with little access to food, clean water, and shelter ${ }^{8,9}$. There has been a failure to tackle the disproportionately negative impact this pandemic has had on certain communities like those living in slums or overcrowded places such as dormitories, prisons, refugee camps, and residential care facilities. Those living in these settings not only faced a greater risk of infection because of an inability to physically distance, but also faced the additional burden of stigma and discrimination because of their unwarranted association with increased transmission risks. Violence against women and the treatment of children and transgender people also adds to these layers of vulnerability ${ }^{10}$.

The pandemic also adversely affected older adults or those with existing co-morbidities who missed their clinical appointments and follow-up care for potentially life-threatening chronic ailments. The lack of physical 'family presence' has also been devastating for dementia patients, among others, who rely on inperson family support ${ }^{11}$. Additionally, millions of children not only missed out on routine immunizations and important healthcare interventions, faced food insecurity, and missed out on faceto-face education, playing with friends, and participating in physical activities ${ }^{12,13}$.

\section{We must learn to improve communication}

Conducting rigorous, expedited research without losing sight of scientific and ethical standards and appropriate dissemination of research results is essential in the context of a public health emergency so that individuals and communities can effectively protect themselves and navigate the 'infodemic' of false and misleading information ${ }^{14}$. Yet, pre-prints of non-refereed studies have increased drastically with a large number of retractions $s^{15}$. Some therapies touted in retracted studies have been the focus of 'panic prescribing', which in some cases has led to harm to patients ${ }^{16}$. To learn from these experiences, two fundamental lessons about research and communication should be understood.

First, in general, evidence-based communication and a researchliterate culture promotes societies that are more resilient to ideology and misinformation, whether in deciding about policies of mask wearing, resource allocation, reopening the economy, or use of unproven interventions ${ }^{17}$. Second, because good decision-making is based on accurate information, developing research skills is an investment for global society's well-being and development, not a mere expense ${ }^{18}$. Hence, carrying out research during pandemic times is at the same time a moral obligation of all countries ${ }^{19}$. Politicians also need to take responsibly for their actions and not indulge in inappropriate involvement in issues of clinical expertise. A key part of any pandemic response is enabling trusted experts to provide clear and transparent translation of scientific findings, including the limitations of those findings, for the public.

\section{Conclusion}

The five ethical lessons identified above are clearly not exhaustive of all ethical lessons or challenges experienced during this pandemic. They were identified by a group of bioethicists, physicians, and public health practitioners from around the world and reflect our collective experience and judgements and should be interpreted as such. Consequently, we have little doubt that serious ethical lessons-perhaps ones even more significant than those we identified-may have been neglected. Nevertheless, we believe that learning these lessons constitutes our greatest moral obligation as this pandemic continues to evolve.

\section{Disclaimer}

The opinions in this open letter are those of the authors and do not necessarily reflect the views of the authors' institutions.

\section{Data availability}

Underlying data

No data are associated with article.
1. Persad G, Emanuel EJ: The ethics of COVID-19 immunity-based licenses ("immunity passports"). JAMA. 2020; 323(22): 2241-2242. Publisher Full Text

2. World Health Organization: Ethical considerations to guide the use of digital proximity tracking technologies for COVID-19 contact tracing. Geneva, Switzerland, WHO/2019-nCoV/Ethics_Contact_tracing_apps/2020.1. Reference Source

3. Emanuel EJ, Persad G, Kern A, et al: An ethical framework for global vaccine allocation. Science. 2020; 369(6509): 1309-1312. PubMed Abstract | Publisher Full Text

4. Smith MJ, Upshur REG: Learning lessons from COVID-19 requires recognizing moral failures. J Bioeth Inq. 2020; 17(4): 563-566. PubMed Abstract | Publisher Full Text | Free Full Text

5. Yamey $G$, Jamison $D$, Hanssen $O$, et al.: Financing global common goods for health: When the world is a country. Health Syst Reform. 2019; 5(4): 334-349. PubMed Abstract | Publisher Full Text

6. World Health Organization: International health regulations. 2005 Reference Source

7. World Bank: Projected poverty impacts of COVID-19 (coronavirus). 2020. Reference Source

8. Guadagno L: Migrants and the COVID-19 pandemic: An initial analysis. International Organization for Migration. 2020. Reference Source

9. Dungdung G: India's coronavirus refugees are also development refugees. Scientific American. 2020. Reference Source

10. Mlambo-Ngcuka P: Violence against women and girls: the shadow 
pandemic. UN Women. 2020.

Reference Source

11. Voo TC, Senguttuvan M, Tam CC: Family presence for patients and separated relatives during COVID-19: Physical, virtual, and surrogate. J Bioeth Inq. 2020; 17(4): 767-772.

PubMed Abstract | Publisher Full Text | Free Full Text

12. Fore HH: A wake-up call: COVID-19 and its impact on children's health and wellbeing. Lancet Glob Health. 2020; 8(7): e861-e862. PubMed Abstract | Publisher Full Text | Free Full Tex

13. Moore SA, Faulkner G, Rhodes RE, et al.: Impact of the COVID-19 virus outbreak on movement and play behaviours of Canadian children and youth: a national survey. Int J Behav Nutr Phys Act. 2020; 17(1): 85. PubMed Abstract | Publisher Full Text | Free Full Text

14. World Health Organization: An ad hoc WHO technical consultation managing the COVID-19 infodemic: call for action. Geneva, Switzerland. Reference Source
15. Bramstedt KA: The carnage of substandard research during the COVID-19 pandemic: a call for quality. J Med Ethics. 2020; 46(12): 803-807. PubMed Abstract | Publisher Full Text

16. Caplan AL, Upshur R: Panic prescribing has become omnipresent during the COVID-19 pandemic. J Clin Invest. 2020; 130(6): 2752-2753. PubMed Abstract | Publisher Full Text | Free Full Text

17. Roozenbeek J, Schneider CR, Dryhurst S, et al.: Susceptibility to misinformation about COVID-19 around the world. $R$ Soc Open Sci. 2020; 7(10): 201199. PubMed Abstract | Publisher Full Text | Free Full Text

18. Dawson A, Emanuel EJ, Parker M, et al.: Key ethical concepts and their application to COVID-19 research. Public Health Ethics. 2020; 13(2): 127-132. Publisher Full Text

19. Nuffield Council on Bioethics: Research in global health emergencies: Ethica issues. 2020.

Reference Source 


\section{Open Peer Review}

\section{Current Peer Review Status:}

\section{Version 1}

Reviewer Report 26 February 2021

https://doi.org/10.21956/wellcomeopenres.18258.r42411

(C) 2021 Serour G. This is an open access peer review report distributed under the terms of the Creative Commons Attribution License, which permits unrestricted use, distribution, and reproduction in any medium, provided the original work is properly cited.

\section{Gamal Serour}

Department of Obstetrics and Gynaecology, Al Azhar University, Cairo, Egypt

The global spread of COVID-19 since the beginning of the last year has struck the world not only with health, educational, economic, and social problems, but also created serious ethical concerns. An International well-qualified group of 17 experts bioethics spanning 15 countries including low, middle, and high income countries met virtually and identified in their opinion the most significant ethical challenges and companying lessons based the world in its combat of COVID-19 pandemic. Five top lessons were identified by the group in this regard and indeed they highlighted important ethical lessons raised when the whole world developed and developing suffer from the unprecedented spread of the COVID-19 pandemic.

The first lesson identified was that the world must learn to prepare adequately to face similar unexpected pandemics to perform better than we did during the current pandemic.

The second lesson was that we must learn the better articulate and priorities overarching goals. No doubt during the pandemic several healthcare, educational, economic, social and mental issues were faced. We globally did not prioritise the overarching goals and kept on complete lockdown, partial lockdown, no lockdown and shifting from one lockdown to another. This resulted in serious impairments of service provided in sexual reproductive health, including contraception, gender based violence, educational services and economic crisis.

The third lesson highlighted how important it is for the world to learn to work collaboratively whether at the governmental levels, UN organizations, Pharmaceutical Industries, private sectors, and civil society organizations.

The fourth lesson was how we should in such circumstances learn to identify and protect the most vulnerable individuals and populations as the elderly, the diseased women and children and not forget specifically health care providers who are almost always at the forefront in saving the lives of our people. The world lost many of the health care providers and elderly because they were not timely provided with the necessary protective equipment and the care they needed. 
The fifth lesson which I believe is an extremely important lesson is that we all in different parts of the world developed, or developing countries must learn to improve our communications to combat better such similar pandemics. The positive achievements, policies, researches and treatment must be communicated to all others immediately for the benefit of the whole of humanity. We are living in a small village and what happens in the far east affects those in the far remote areas whether Africa, Europe, North America or South America and vice versa.

No doubt these are important ethical lessons identified by this expert group and they admit that these five lessons are not exhausted of all ethical lessons or challenges, experienced during this pandemic and I could not agree more.

Is the rationale for the Open Letter provided in sufficient detail?

Yes

Does the article adequately reference differing views and opinions?

Yes

Are all factual statements correct, and are statements and arguments made adequately supported by citations?

Yes

Is the Open Letter written in accessible language?

Yes

Where applicable, are recommendations and next steps explained clearly for others to follow?

Yes

Competing Interests: No competing interests were disclosed.

Reviewer Expertise: Bioethics, Infertility, SRHR, Assisted reproductive technology.

I confirm that I have read this submission and believe that I have an appropriate level of expertise to confirm that it is of an acceptable scientific standard.

Reviewer Report 15 February 2021

https://doi.org/10.21956/wellcomeopenres.18258.r42415

(C) 2021 Ortiz-Millan G. This is an open access peer review report distributed under the terms of the Creative Commons Attribution License, which permits unrestricted use, distribution, and reproduction in any medium, provided the original work is properly cited.

Gustavo Ortiz-Millan 
Institute for Philosophical Research, National Autonomous University of Mexico, Mexico City, Mexico

It is true that we must learn to prepare adequately based on previous experience. It is also true that we have also been slow to learn from the experiences of other countries that were affected earlier in this pandemic. However, we have also been slow to learn from previous pandemics. The rate at which epidemics have appeared in the last 30 or 40 years has been greater than ever before. When the authors talk about the obligation to prepare adequately, they focus on "features of public health systems such as adequate surveillance, stockpiles of personal protective equipment, testing, contact tracing, the identification of at-risk populations, and other nonpharmaceutical interventions." I wonder whether by "adequate surveillance" they are also thinking about surveillance of zoonotic outbreaks.

There is something that we have not learned despite having gone through other epidemics in recent times: the origin of this pandemic is in the way we relate to animals and exploit them. Similar epidemics that we have seen in recent decades have their origin in zoonotic outbreaks, that is, they were transmitted from animals to humans. According to the CDC, three out of every four emerging infectious diseases in people come from animals. ${ }^{1}$ Recent pandemics such as HIV/AIDS, ${ }^{2}$ Ebola, ${ }^{3}$ MERS, ${ }^{4} \mathrm{H} 7 \mathrm{~N} 9,{ }^{5} \mathrm{H} 1 \mathrm{~N} 1,{ }^{5} \mathrm{H} 5 \mathrm{~N} 1,{ }^{6}$ and SARS (now known as SARS-CoV- 1 ), ${ }^{7}$ among others have a zoonotic origin. Many (if not all) of them arose in contexts of exploitation of animals (wild or domestic), such as the trade-legal or illegal-of wildlife species, or the production of meat in intensive systems in factory farms. Some even took place in "wet markets" in China or Southeast Asia-such as H5N1, H7N9 and the SARS epidemics. ${ }^{8}$ Wildlife trade and factory farms have grown in recent years, oftentimes in contexts of little or no regulation or supervision by the health and environmental authorities of the countries where these activities take place, but sometimes in contexts of illegality. These types of activities have increased the likelihood of outbreaks of emerging infectious diseases.

Some epidemic diseases also have an environmental origin, related to the invasion of habitats and to the close contact that the natural reservoir fauna is forced to have with domestic animals and, ultimately, with humans. They also have to do with biodiversity loss and the increasing prevalence of certain pathogens in reservoir populations. If biodiversity does not deteriorate, reservoir populations are diluted among other species, and the risk of pathogens transmission is reduced. Apparently, we have not learned much from previous pandemics, but if there is a lesson to be learned from the current one, is that if we do not modify our relationship with animals (and nature in general), it is very likely that we will see the emergence of other zoonotic pandemics in the near future.

\section{References}

1. Centers for Disease Control and Prevention: Zoonotic diseases. 2017. Reference Source 2. Hahn BH, Shaw GM, De Cock KM, Sharp PM: AIDS as a zoonosis: scientific and public health implications.Science. 2000; 287 (5453): 607-14 PubMed Abstract | Publisher Full Text 3. Pigott DM, Golding N, Mylne A, Huang Z, et al.: Mapping the zoonotic niche of Ebola virus disease in Africa.Elife. 2014; 3: e04395 PubMed Abstract | Publisher Full Text

4. Li F, Du L: MERS Coronavirus: An Emerging Zoonotic Virus. Viruses. 2019; 11 (7). Publisher Full Text

5. World Health Organization: Influenza (Avian and other zoonotic). 2018. Reference Source 6. Kandeel A, Manoncourt S, Abd el Kareem E, Mohamed Ahmed AN, et al.: Zoonotic transmission of avian influenza virus (H5N1), Egypt, 2006-2009.Emerg Infect Dis. 2010; 16 (7): 1101-7 PubMed Abstract | Publisher Full Text 
7. Hu B, Zeng LP, Yang XL, Ge XY, et al.: Discovery of a rich gene pool of bat SARS-related coronaviruses provides new insights into the origin of SARS coronavirus.PLoS Pathog. 2017; 13 (11): e1006698 PubMed Abstract | Publisher Full Text

8. Walters MJ: Seven Modern Plagues and How We are Causing Them. Island Press. 2014.

Is the rationale for the Open Letter provided in sufficient detail?

Yes

Does the article adequately reference differing views and opinions?

Yes

Are all factual statements correct, and are statements and arguments made adequately supported by citations?

Yes

Is the Open Letter written in accessible language?

Yes

Where applicable, are recommendations and next steps explained clearly for others to follow?

Yes

Competing Interests: No competing interests were disclosed.

Reviewer Expertise: Bioethics

I confirm that I have read this submission and believe that I have an appropriate level of expertise to confirm that it is of an acceptable scientific standard. 